\title{
Analisis Stabilitas Lereng dalam Penanganan Longsoran di Jalan Tol Cipularang Km. 91+200 dan Km. 92+600 Menggunakan Metode Elemen Hingga (FEM)
}

\author{
Indra Noer Hamdhan ${ }^{1}$, Desti Santi Pratiwi ${ }^{2}$ \\ ${ }^{1}$ Jurusan Teknik Sipil, Fakultas Teknik Sipil dan Perencanaan, ITENAS, Bandung \\ ${ }^{2}$ Program Studi Magister Teknik Sipil, Fakultas Teknik Sipil dan Lingkungan, \\ ITB-Bandung \\ Email : indranh@itenas.ac.id
}

\begin{abstract}
ABSTRAK
Longsoran terjadi di Jalan Tol Cipularang Km. 91+200 dan Km. 92+600. Longsoran terjadi karena adanya pergerakan pada lapisan batu lempung (clay shale), sehingga perlu adanya penanganan longsoran secara tepat dan efektif. Penanganan yang dipilih, yaitu dengan pemasangan perkuatan lereng berupa boredpile dan dinding penahan tanah. Dimensi boredpile yang digunakan yaitu berdiameter $80 \mathrm{~cm}$. Analisis dilakukan dengan menggunakan Program Plaxis 2D yang berbasis metode elemen hingga, dengan memodelkan 2 (dua) kondisi yaitu kondisi eksisting dan kondisi dengan perkuatan. Analisis pada kondisi eksisting dilakukan dengan cara back analysis, sehingga hasil analisis kondisi eksisting sesuai dengan kejadian di lapangan. Analisis dilakukan di 6 (enam) titik untuk Km. 91+200 dan 2 (dua) titik untuk Km. 92+600. Dari hasil analisis didapat bahwa dengan adanya perkuatan pada lereng yang terjadi kelongsoran, nilai faktor keamanan naik hingga 242.2\% dari kondisi eksisting.
\end{abstract}

KataKunci: Longsor, Tol Cipularang, Km. 91+200 dan 92+600, Boredpile, Metode Elemen Hingga, faktor keamanan

\begin{abstract}
The landslide are occurred at Cipularang toll road Km. 91+200 and Km. 92+600. The landslide occur because of the movement of clay shale soil layer, it means should be handled witih appropriate and effective way. For this case, reinforcement slope using boredpile and gravity wall are choosen. Dimension of the boredpile is $80 \mathrm{~cm}$. The analysis was calculated using Plaxis 2D with finite element method with two different type of calculating model : existing condition (without reinforcement) and with reinforcement condition. Analysis for existing model are done by back analysis method that will gave the real condition from the field. The analysis are done by calculated in 6 (six) point area of slope for Km. 91+200 and 2 (two) point area of slope for Km. 92+600. The safety factor (SF) of the slope will increase up to $214 \%$ after reinforcement.
\end{abstract}

Keywords: Landslide, Cipularang Toll Road, Km. 91+200 and 92+600, Boredpile, Finite Element Method, Safety Factor 


\section{PENDAHULUAN}

Longsoran terjadi di Jalan Tol Cipularang Km. 91+200 dan Km. 92+600. Longsoran terjadi diakibatkan adanya pergerakan tanah pada lapisan batu lempung (clay shale). Oleh sebab itu, untuk menangani longsoran tersebut diperlukan adanya suatu penanganan perkuatan lereng permanen dengan tepat, cepat dan efektif. Pada laporan ini, akan menampilkan anaisis perencanaan penanganan longsoran dan diharapkan dapat digunakan untuk permasalahan longsoran ini.

Maksud dan Tujuan penelitian ini adalah melakukan analisis stabilitas lereng untuk penanganan longsoran yang terjadi di Ruas Jalan Tol Cipularang Km. 91+200 dan Km. 92+600 menggunakan Program PLAXIS 2D yang berbasis Elemen Hingga, sehingga dapat menghasilkan sebuah perencanaan penanganan longsoran yang efektif dan tepat secara permanen.

Adapun lokasi longsoran yang akan diberikan penangan disajikan pada Gambar 1

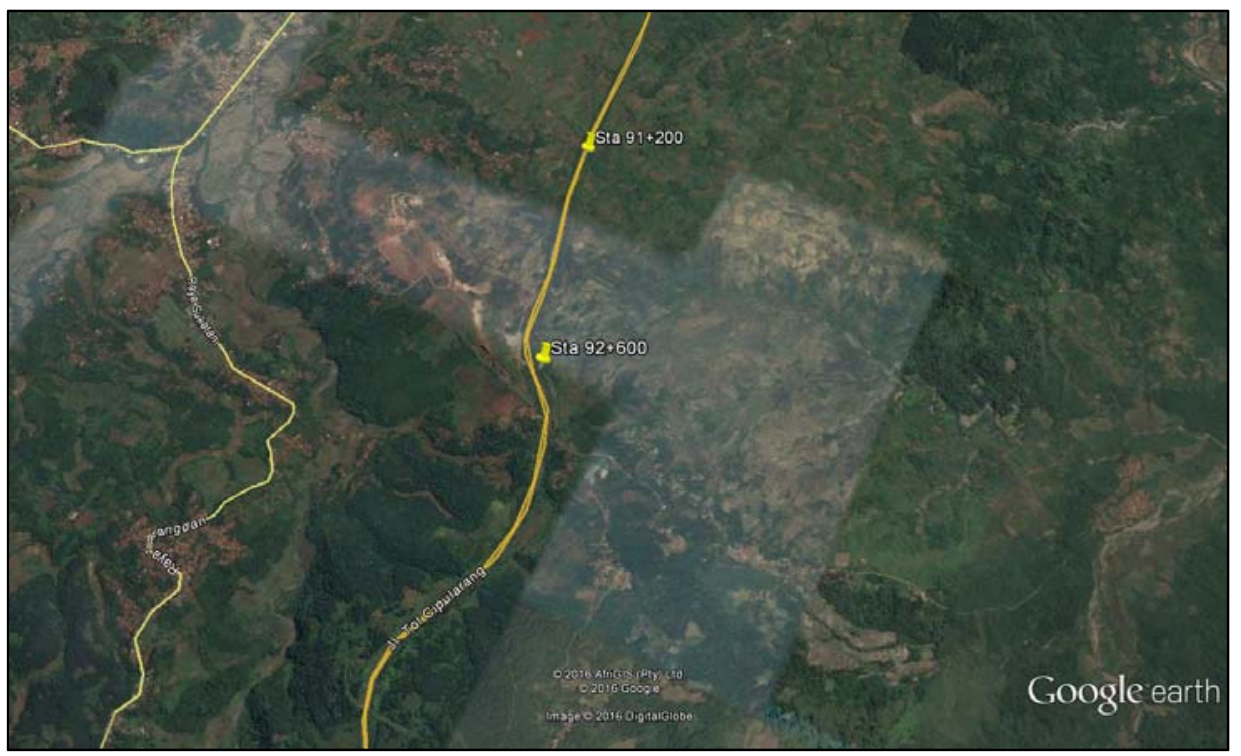

Gambar 1 Lokasi longsoran yang akan ditangani.

\section{TINJAUAN PUSTAKA}

\subsection{Penyebab Gerakan Tanah dan Longsoran pada Lereng}

Lereng merupakan suatu permukaan tanah yang membentuk suatu sudut tertentu terhadap bidang horizontal sehingga menimbulkan sebuah kemiringan. Lereng dibedakan menjadi dua, yaitu lereng alami dan lereng buatan. Lereng yang terbentuk sendirinya akibat kejadian alam atau lingkungan disebut lereng alami, sedangkan lereng yang dibuat oleh manusia yang dapat berupa pemotongan tebing atau pembuatan lereng disebut lereng buatan. [6]

Pergerakan tanah dan longsoran pada lereng dapat disebabkan oleh alam maupun oleh manusia, hal tersebut sulit untuk dihindari. Pergerakan tanah yang diakibatkan oleh alam dapat berupa unsur geologi, iklim dan topografi, sedangkan yang disebabkan oleh manusia yaitu berupa penggalian lereng. [6]

Longsoran dan pergerakan tanah terjadi akibat kekuatan geser (tahanan geser) pada tanah lebih kecil dibandingkan dengan beban (tegangan geser). Adapun faktor yang dapat meningkatkan tegangan geser dan menurunkan kekuatan geser pada lereng, yaitu sebagai berikut [6]: 
a)

Faktor-faktor yang menyebabkan peningkatan tegangan geser

Semakin tinggi nilai tegangan geser, maka potensi untuk terjadi longsor/ pergerakan tanah akan semakin besar. Peningkatan tegangan geser pada tanah dapat diakibatkan dari hilangnya dukungan arah lateral dan vertikal, seperti erosi sungai, proses pelapukan, penggalian permukaan oleh manusia, dan penambangan. Adapun penyebab meningkatnya tegangan geser dari beban permukaan dan beban lain, seperti pelaksanaan timbunan, terdapat beban bangunan dan konstruksi sipil yang lain, vegetasi, akumulasi talus, air hujan yang merembes ke dalam tanah atau rekahan, dan tekanan rembesan.

b) Faktor-faktor yang menyebabkan penurunan kekuatan geser (tahanan geser)

Faktor-faktor yang dapat menyebabkan penurunan kuat geser dalam tanah, yaitu meningktanya kadar air, fissured clay mengalami pelembekan, dan disintegrasi fisis dari batuan, misalnya pada clayshale.

\subsection{Teori Keruntuhan Mohr Coulomb}

Mohr (1900) memperkenalkan sebuah teori tentang keruntuhan yang dikenal dengan Teori keruntuhan Mohr Coulomb, yang menyatakan bahwa keruntuhan terjadi pada suatu material akibat kombinasi kritis antara tegangan normal dan geser, bukan hanya akibat tegangan normal dan geser dalam kondisi maksimum saja [5]. Persamaan kriteria keruntuhan Mohr-Coulomb yang dapat ditulis menjadi persamaan berikut ini [2]:

$$
\tau \mathrm{f}=\mathrm{c}+\sigma \tan \phi
$$

Dimana :

$\mathrm{c}=$ kohesi

$\phi=$ sudut geser dalam

Keruntuhan geser tidak akan terjadi jika tegangan normal dan geser bekerja pada suatu bidang massa tanah, sedangkan keruntuhan geser akan terjadi jika tegangan normal dan geser tepat pada garis keruntuhan. Apabila tegangan normal dan geser berada di atas garis keruntuhan MohrCoulomb tidak mungkin terjadi, maka kondisi tersebut keruntuhan gesernya sudah terjadi.

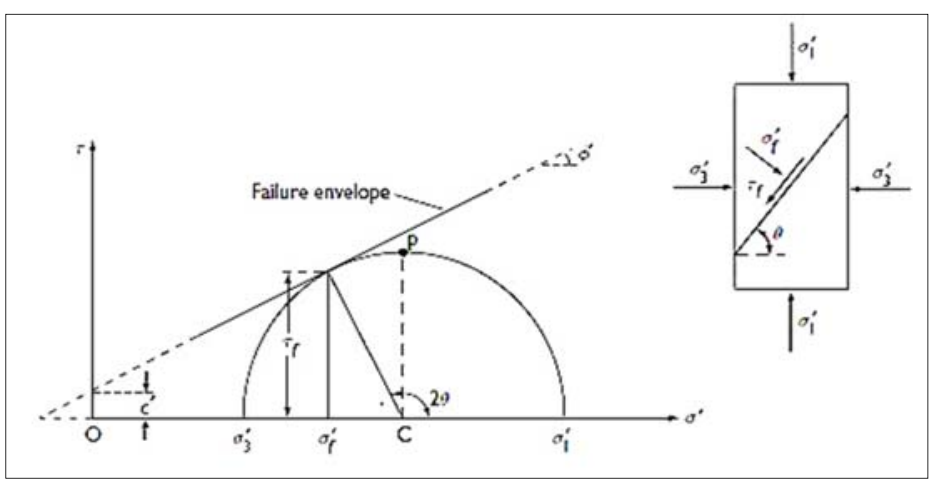

Gambar 2 Keruntuhan Mohr Coulomb [3]

\subsection{Pemilihan Tipe Penanganan Longsoran}

Pemilihan tipe penanganan longsoran yang dipilih tergantung dari tipe longsoran yang terjadi dan kemudahan pelaksanaannya di lapangan. Adapun beberapa aspek yang perlu diperhatikan dan dipertimbangkan dalam menentukan penanggulangan longsoran, yaitu aspek topografi, aspek geologi, aspek geometri jalan, aspek geoteknik, aspek hidrologi dan hidrogeologi, aspek lingkungan, dan aspek ketersediaan bahan atau material konstruksi.

Berdasarkan prinsip dasar penanggulangan gerakan tanah/ longsoran [4], prosedur dalam perencanaan kestabilan lereng dapat dibagi menjadi 3 kategori, yaitu:

a) Mengeliminasi masalah, seperti pembuangan/ penggantian material lereng, pembuatan jembatan, atau relokasi lereng

Rekayasa Hijau - 102 
b) Mereduksi gaya-gaya yang mengakibatkan kelongsoran, seperti memberikan drainase di permukaan dan sub drain, perubahan geometri lereng, dan pengurangan berat beban di area lereng

c) Meningkatkan gaya-gaya yang menahan kelongsoran atau memberikan kestabilan pada lereng, misalnya konstruksi dinding penahan tanah, pemasangan turap, penggunaan perkuatan lereng seperti turap dan boredpile, dan penggunaan bahan kimia.

\subsection{Analisis Stabilitas Lereng dengan Menggunakan Metode Elemen Hingga (FEM)}

Kelongsoran tanah aktif dapat distabilkan dengan penggunaan pile. Dalam menganalisis besar tekanan tanah yang terjadi pada pile, terdapat beberapa metode yang dapat digunakan. Salah satu metode yang dapat digunakan yaitu metode berbasis numerik yang dapat digunakan pada kasuskasus rumit dan dapat menghasilkan hasil yang baik. Adapun beberapa keuntungan dari penggunaan metode numerik untuk analisis stabilitas lereng, yaitu dapat digunakan untuk analisis lereng dengan longsoran yang kompleks, dapat memasukkan kondisi regangan tegangan yang ada pada lereng dalam perhitungan kestabilan lereng, dapat menggunakan berbagai macam kriteria keruntuhan, dan dapat dengan mudah memasukkan efek perkuatan pada lereng.

Metode Elemen Hingga (Finite-Element Method) merupakan salah satu metode numerik yang sering digunakan saat ini. Metode ini membuat persamaan matematis dengan berbagai pendekatan dan rangkaian persamaan aljabar yang melibatkan nilai-nilai pada titik-titik diskrit pada bagian yang dievaluasi. Pada metode elemen hingga, daerah yang dianalisis dibagi kedalam beberapa elemen.

Terdapat pendekatan yang umum digunakan dalam menganalisis stabilitas lereng dengan menggunakan metode elemen hingga ini, yaitu metode pengurangan kekuatan geser (strength reduction method). Metode ini memiliki prinsip dengan mereduksi/mengurangi kekuatan geser material secara bertahap sampai membentuk suatu mekanisme keruntuhan pada lereng [1]. Adapun nilai parameter kohesi (c) dan sudut geser $(\phi)$ yang akan direduksi, yang dinyatakan dengan persamaaan sebagi berikut:

$$
\begin{gathered}
c_{f}=\frac{c}{S R F} \ldots \ldots \ldots \\
\emptyset_{f}=\tan ^{-1}\left(\frac{\tan \emptyset}{S R F}\right)
\end{gathered}
$$

Dimana :

$\mathrm{SRF}=$ faktor reduksi kekuatan geser

Faktor keamanan (SF) besarnya sama dengan nilai SRF pada saat tepat terjadi keruntuhan

\section{ANALISIS DATA}

\subsection{Pemodelan Lereng}

Analisis dilakukan dalam 2 (dua) kondisi, yaitu kondisi eksisting dan kondisi dengan perkuatan lereng. Perkuatan lereng yang digunakan, yaitu kombinasi antara boredpile dengan dinding penahan tanah atau pilecap. Analisis dilakukan untuk 2 (dua) lokasi, yaitu di Km. 91+200 dan Km. $92+600$, dengan pemodelan lereng di 6 (enam) titik untuk Km. 91+200 dan 3 (tiga) titik untuk Km. $92+600$. Pemodelan geometri diambil dari gambar desain potongan melintang Km. 91+200 dan Km. $92+600$.

\subsection{Analisis Stabilitas Lereng di Jalan Tol Cipularang Km. 91+200}

Dalam menganalisis stabilitas lereng, hal pertama yang perlu dilakukan yaitu survey pendahuluan untuk mengetahui kondisi eksisting di lapangan. Dari hasil survey pedahuluan didapatkan adanya longsoran yang telah terjadi, dan adanya pembentukkan crown di badan jalan. Di lapangan pun ditemukan adanya lapisan batu lempung (clayshale), yang dapat menjadi penyebab kelongoran lereng di lokasi ini. Clayshale memiliki sifat kompresibilitas, dimana clayshale akan terurai jika terkena air. Adapun dokumentasi hasil survey pendahuluan di tunjukkan pada Gambar 3. 


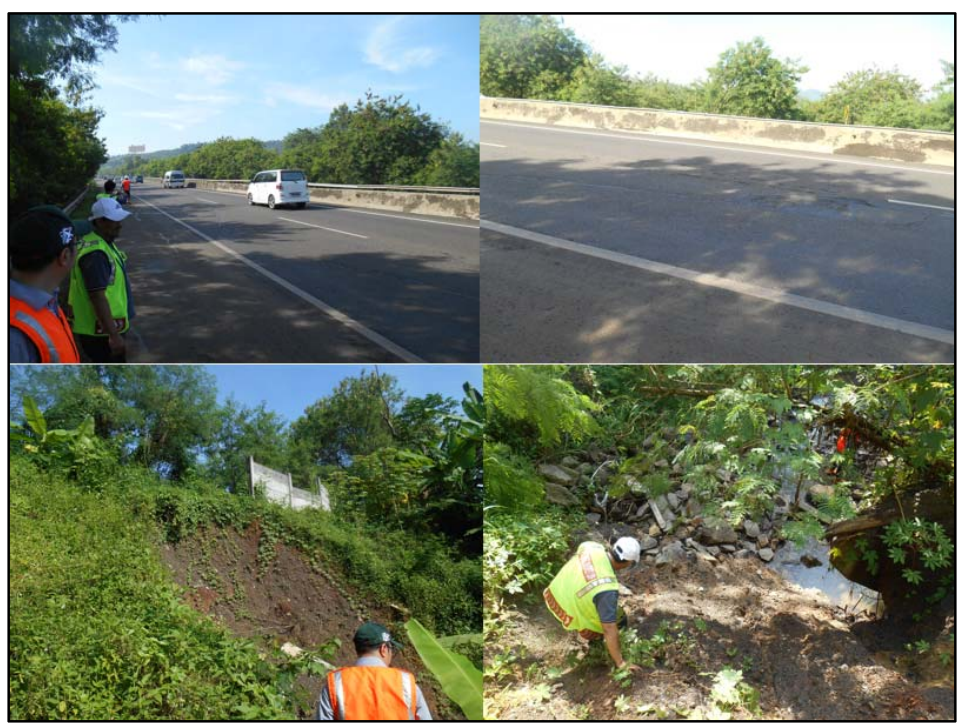

Gambar 3 Dokumentasi lapangan di Km. 91+200.

Pemodelan analisis stabilitas lereng di Km. 91+200 dilakukan di 6 (enam) lokasi, yaitu Km. 91+250, Km. 91+256.081, Km. 91+270, Km. 91+300, Km. 91+340, dan Km. 91+400. Dalam pemodelan lokasi ini, parameter yang tanah yang digunakan disajikan pada Tabel 1.

Tabel 1 Parameter Tanah yang Digunakan untuk Pemodelan di Km. 91+200

\begin{tabular}{cccccccc}
\hline \multirow{2}{*}{ Lapis } & Jenis Tanah & Tipe & $\gamma_{\text {unsat }}$ & $\gamma_{\text {sat }}$ & $\mathbf{E}_{\mathbf{r e f}}$ & $\mathbf{C}_{\mathbf{r e f}}$ & $\boldsymbol{\phi}$ \\
\cline { 5 - 7 } & $\mathbf{k N} / \mathbf{m}^{\mathbf{3}}$ & $\mathbf{k N} / \mathbf{m}^{\mathbf{3}}$ & $\mathbf{k N} / \mathbf{m}^{\mathbf{2}}$ & $\mathbf{k N} / \mathbf{m}$ & $\mathbf{0}$ \\
\hline 1 & Lempung batu gravel & Undrained & 23 & 24 & 5000 & 20 & 13 \\
\hline 2 & $\begin{array}{c}\text { Lempung coklat } \\
\text { kemerahan teguh }\end{array}$ & Undrained & 17 & 18 & 6720 & 18 & 11 \\
\hline 3 & $\begin{array}{c}\text { Lempung tufa pasir } \\
\text { halus }\end{array}$ & Undrained & 16 & 17 & 6400 & 18 & 13 \\
\hline 4 & $\begin{array}{c}\text { Lempung tufa } \\
\text { kemerahan }\end{array}$ & Undrained & 19 & 20 & 13440 & 16.2 & 12 \\
\hline 5 & $\begin{array}{c}\text { Lempung tufa sangat } \\
\text { keras }\end{array}$ & Undrained & 23 & 24 & 22500 & 45 & 15 \\
\hline
\end{tabular}

a) Analisis Kestabilan Lereng di Km. 91+250

Analisis pemodelan dilakukan dalam 2 (dua) kondisi, yaitu kondisi eksisting dan kondisi perkuatan. Pemodelan analisis stabilitas lereng dilakukan dengan metode elemen hingga (FEM). Pemodelan geometri pada kondisi eksisting dan hasil analisis berupa bidang gelincir disajikan pada Gambar 4. Pemodelan dilakukan dengan menggunakan parameter tanah hasil uji laboratorium dan korelasi data N-SPT sehingga diperoleh faktor keamanan lereng dari hasil analisis kondisi eksisting ini adalah sebesar 1.148 . 


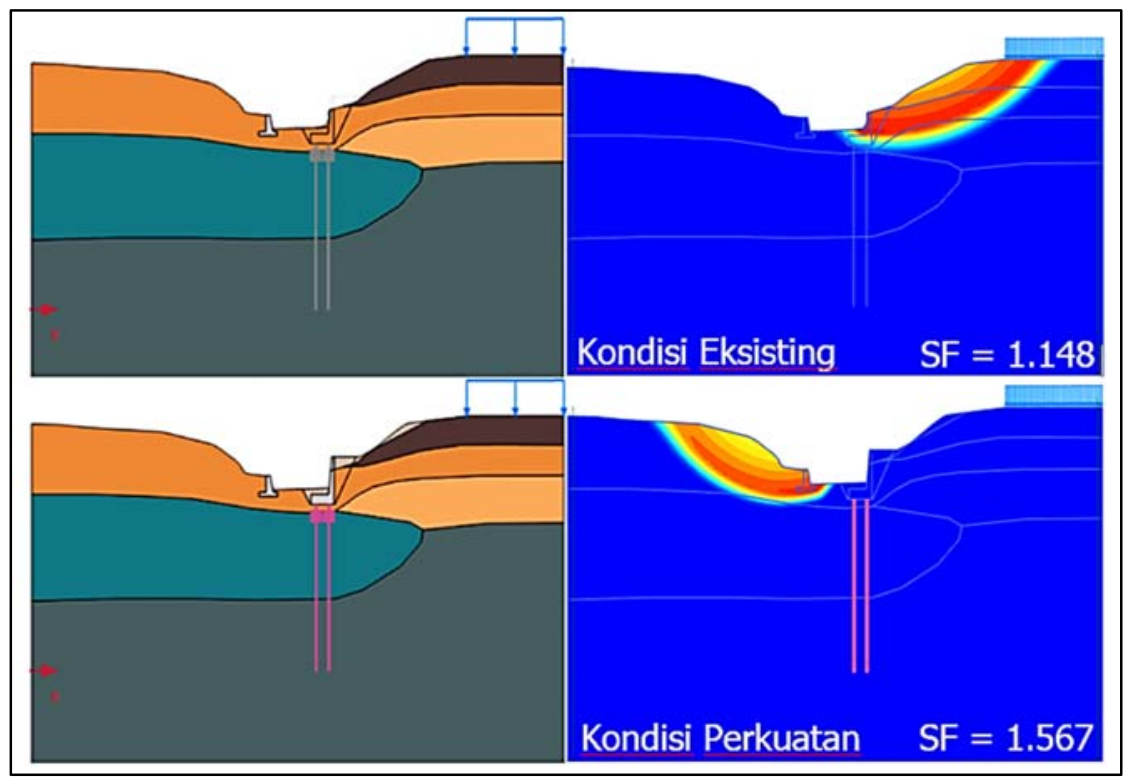

Gambar 4 Hasil analisis kondisi eksisting dan perkuatan di Km. 91+250.

Nilai faktor keamanan yang dihasilkan dari analisis kondisi eksisting kurang dari 1.5, sehingga perlu adanya perkuatan lereng agar menghasilkan nilai faktor keamanan di atas 1.5. Adapun perkuatan lereng yang disarankan yaitu pemasangan dinding penahan tanah dan boredpile yang dipasang 2 (dua) baris/zigzag. Boredpile yang direncanakan berdiameter $80 \mathrm{~cm}$ dan kedalaman tiang $20 \mathrm{~m}$ dengan mutu beton K-350. Hasil analisis pemodelan dengan kondisi perkuatan ditunjukkan pada Gambar 4 dengan nilai faktor keamanan sebesar 1.567.

b) Analisis Kestabilan Lereng di Km. 91+256.081

Analisis pemodelan dilakukan dalam 2 (dua) kondisi, yaitu kondisi eksisting dan kondisi perkuatan. Pemodelan analisis stabilitas lereng dilakukan dengan metode elemen hingga (FEM). Pemodelan geometri pada kondisi eksisting dan hasil analisis berupa bidang gelincir disajikan pada Gambar 5. Pemodelan dilakukan dengan menggunakan parameter tanah hasil uji laboratorium dan korelasi data N-SPT sehingga diperoleh faktor keamanan lereng dari hasil analisis kondisi eksisting ini adalah sebesar 1.243 .

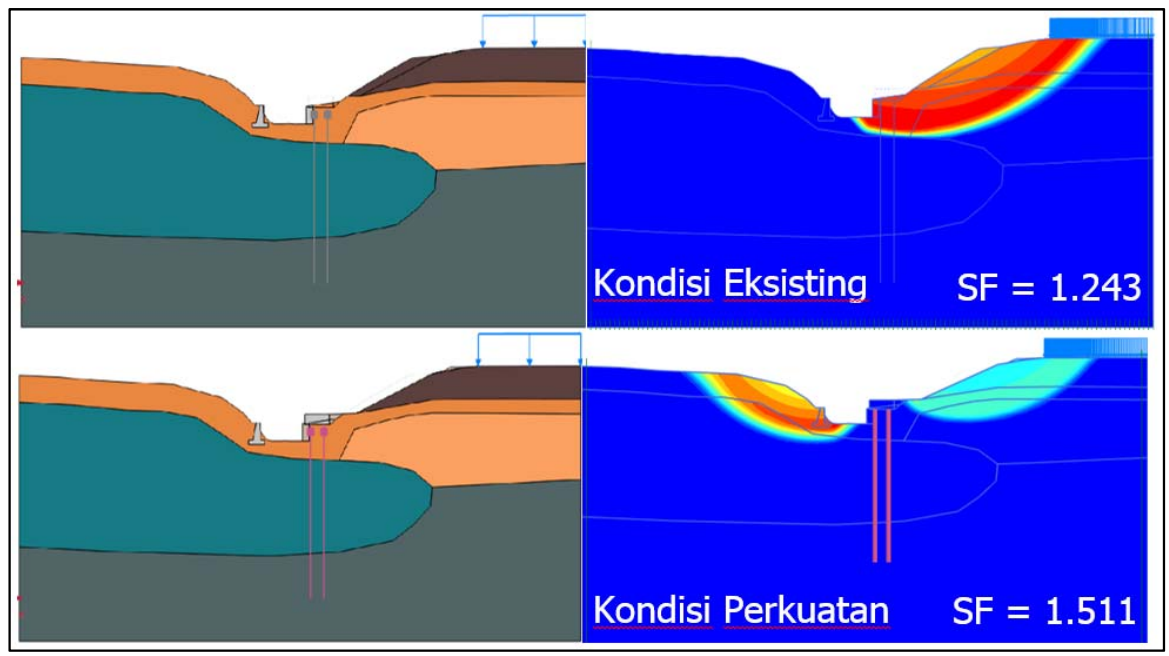

Gambar 5 Hasil analisis kondisi eksisting dan perkuatan di Km. 91+256.081. 
Nilai faktor keamanan yang dihasilkan dari analisis kondisi eksisting kurang dari 1.5, sehingga perlu adanya perkuatan lereng agar menghasilkan nilai faktor keamanan di atas 1.5. Adapun perkuatan lereng yang disarankan yaitu pemasangan pilecap dan boredpile yang dipasang 2 (dua) baris berpola zigzag. Boredpile yang direncanakan berdiameter $80 \mathrm{~cm}$ dan kedalaman tiang $20 \mathrm{~m}$ dengan mutu beton K-350. Hasil analisis pemodelan dengan kondisi perkuatan ditunjukkan pada Gambar 5 dengan nilai faktor keamanan sebesar 1.511.

c) Analisis Kestabilan Lereng di Km. 91+270

Analisis pemodelan dilakukan dalam 2 (dua) kondisi, yaitu kondisi eksisting dan kondisi perkuatan. Pemodelan analisis stabilitas lereng dilakukan dengan metode elemen hingga (FEM). Pemodelan geometri pada kondisi eksisting dan hasil analisis berupa bidang gelincir disajikan pada Gambar 6. Pemodelan dilakukan dengan menggunakan parameter tanah hasil uji laboratorium dan korelasi data N-SPT sehingga diperoleh faktor keamanan lereng dari hasil analisis kondisi eksisting ini adalah sebesar 1.419 .

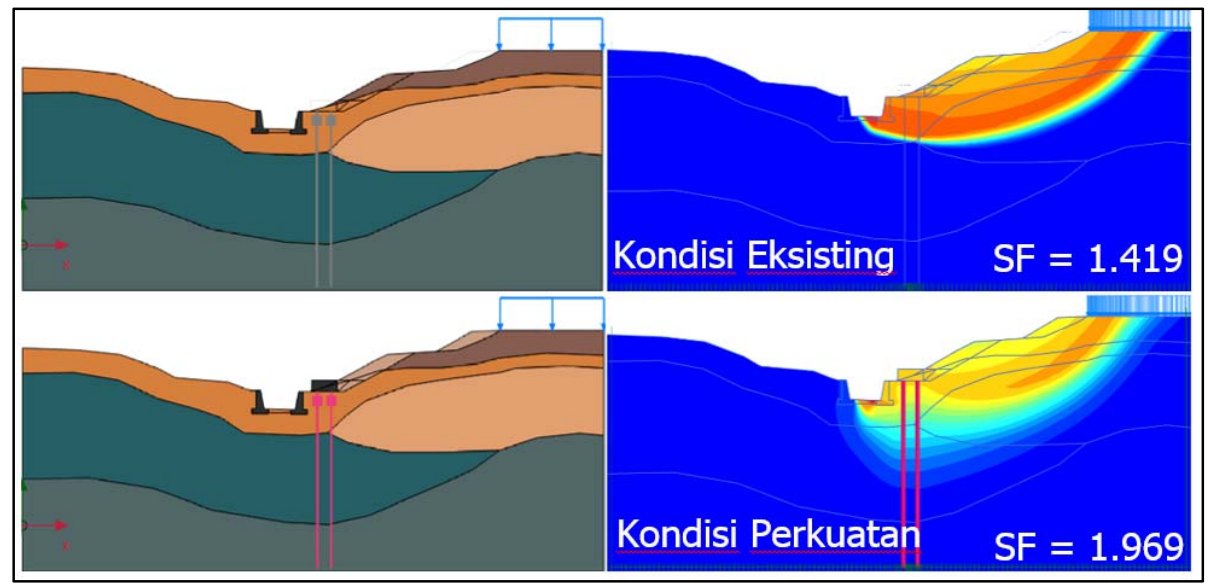

Gambar 6 Hasil analisis kondisi eksisting dan perkuatan di Km. 91+270.

Nilai faktor keamanan yang dihasilkan dari analisis kondisi eksisting kurang dari 1.5, sehingga perlu adanya perkuatan lereng agar menghasilkan nilai faktor keamanan di atas 1.5. Adapun perkuatan lereng yang disarankan yaitu pemasangan pilecap dan boredpile yang dipasang 2 (dua) baris dengan pola pemasangan zigzag. Boredpile yang direncanakan berdiameter $80 \mathrm{~cm}$ dan kedalaman tiang $20 \mathrm{~m}$ dengan mutu beton untuk boredpile, yaitu K-350. Hasil analisis pemodelan dengan kondisi perkuatan ditunjukkan pada Gambar 6 dengan nilai faktor keamanan sebesar 1.969 .

d) Analisis Kestabilan Lereng di Km. 91+300

Analisis pemodelan dilakukan dalam 2 (dua) kondisi, yaitu kondisi eksisting dan kondisi perkuatan. Pemodelan analisis stabilitas lereng dilakukan dengan metode elemen hingga (FEM). Pemodelan geometri pada kondisi eksisting dan hasil analisis berupa bidang longsor yang disajikan pada Gambar 7. Pemodelan dilakukan dengan menggunakan parameter tanah hasil uji laboratorium dan korelasi data N-SPT sehingga diperoleh faktor keamanan lereng dari hasil analisis kondisi eksisting ini adalah sebesar 1.454 . 


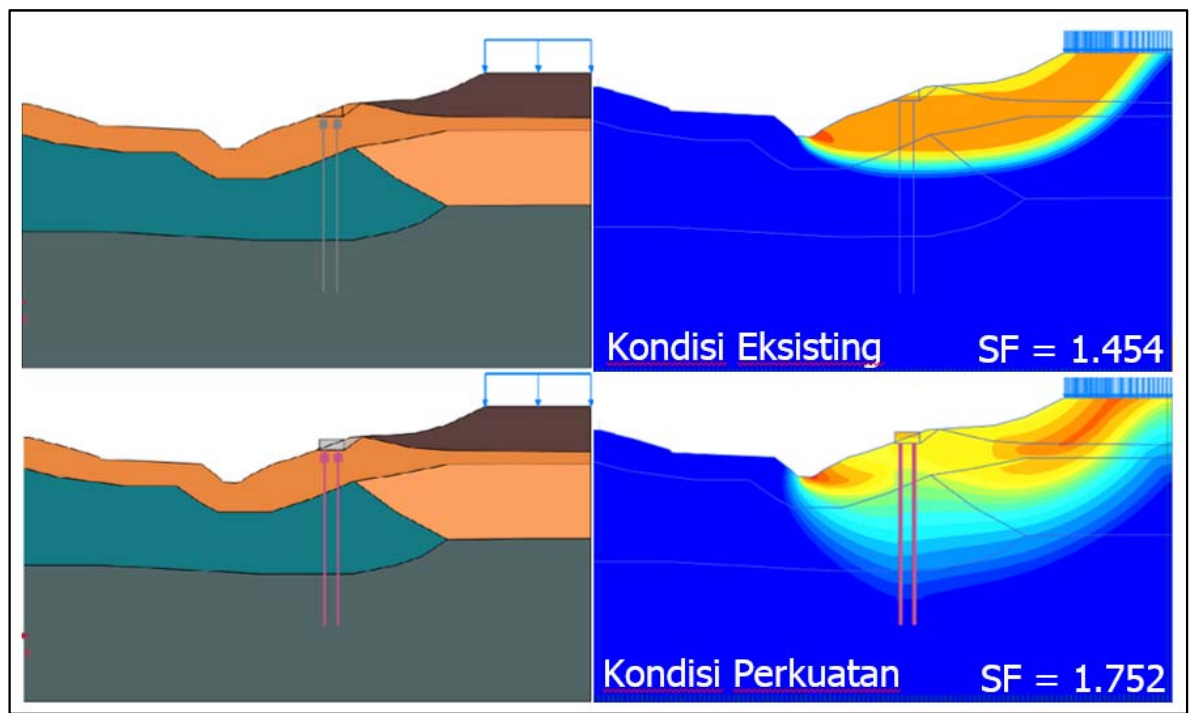

Gambar 7 Hasil analisis kondisi eksisting dan perkuatan di Km. 91+300.

Nilai faktor keamanan yang dihasilkan dari analisis kondisi eksisting kurang dari 1.5, sehingga perlu adanya perkuatan lereng agar menghasilkan nilai faktor keamanan di atas 1.5. Adapun perkuatan lereng yang disarankan yaitu pemasangan boredpile yang dipasang 2 (dua) baris/zigzag. Boredpile yang direncanakan berdiameter $80 \mathrm{~cm}$ dan kedalaman tiang $20 \mathrm{~m}$ dengan mutu beton K350. Hasil analisis pemodelan dengan kondisi perkuatan ditunjukkan pada Gambar 7 dengan nilai faktor keamanan sebesar 1.752 .

e) Analisis Kestabilan Lereng di Km. 91+340

Analisis pemodelan dilakukan dalam 2 (dua) kondisi, yaitu kondisi eksisting dan kondisi perkuatan. Pemodelan analisis stabilitas lereng dilakukan dengan metode elemen hingga (FEM). Pemodelan geometri pada kondisi eksisting dan hasil analisis berupa bidang gelincir disajikan pada Gambar 8. Pemodelan dilakukan dengan menggunakan parameter tanah hasil uji laboratorium dan korelasi data N-SPT sehingga diperoleh faktor keamanan lereng dari hasil analisis kondisi eksisting ini adalah sebesar 1.473 .

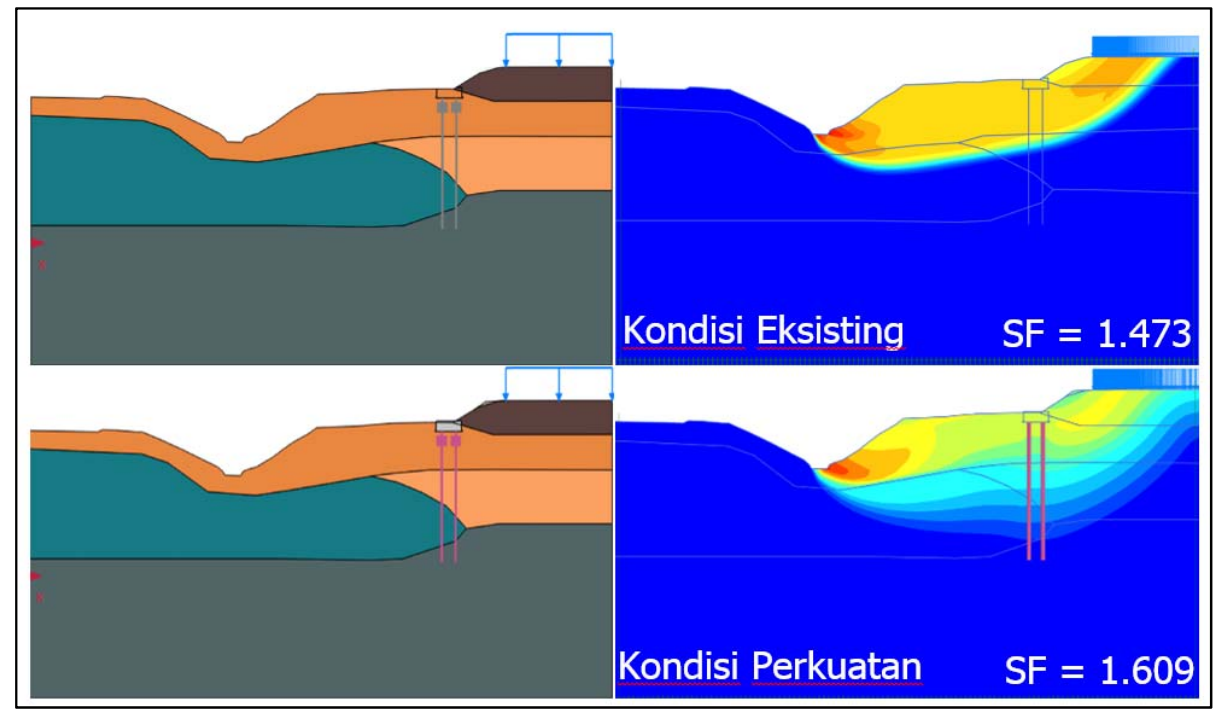

Gambar 8 Hasil analisis kondisi eksisting dan perkuatan di Km. 91+340. 
Nilai faktor keamanan yang dihasilkan dari analisis kondisi eksisting kurang dari 1.5, sehingga perlu adanya perkuatan lereng agar menghasilkan nilai faktor keamanan di atas 1.5. Adapun perkuatan lereng yang disarankan yaitu pemasangan pilecap dan boredpile yang dipasang 2 (dua) baris dengan pola pemasangan zigzag. Boredpile yang direncanakan berdiameter $80 \mathrm{~cm}$ dan kedalaman tiang $15 \mathrm{~m}$ dengan mutu beton K-350. Hasil analisis pemodelan dengan kondisi perkuatan ditunjukkan pada Gambar 8 dengan nilai faktor keamanan sebesar 1.609.

f) Analisis Kestabilan Lereng di Km. 91+400

Analisis pemodelan dilakukan dalam satu kondisi, yaitu kondisi eksisting saja. Pada kondisi eksisting telah terdapat perkuatan bronjong di lapangan, sehingga pemodelan dilakukan untuk mengetahui kondisi eksisting dengan bronjong. Pemodelan analisis stabilitas lereng dilakukan dengan metode elemen hingga (FEM). Pemodelan geometri pada kondisi eksisting dan hasil analisis berupa bidang gelincir disajikan pada Gambar 9. Pemodelan dilakukan dengan menggunakan parameter tanah hasil uji laboratorium dan korelasi data N-SPT sehingga diperoleh faktor keamanan lereng dari hasil analisis kondisi eksisting ini adalah sebesar 1.672. Pemodelan dengan perkuatan tidak dilakukan karena SF eksisting sudah lebih dari 1.5.

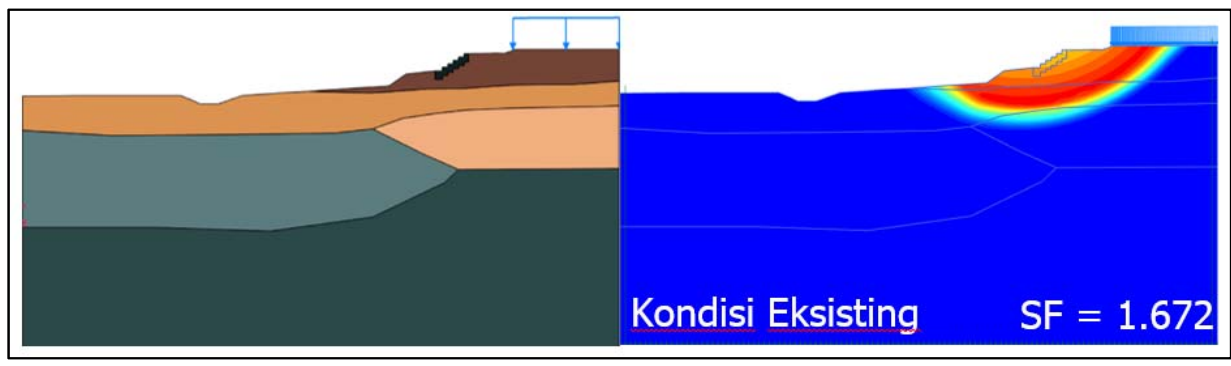

Gambar 9 Hasil analisis kondisi eksisting di Km. 91+400.

\subsection{Analisis Stabilitas Lereng di Jalan Tol Cipularang Km. 92+600}

Sama hal nya dengan perencanaan penanganan longsoran di Km. 91+200, survey pendahuluan pun dilakukan di lokasi longsoran Km. 92+600. Dari hasil survey pendahuluan terdapat beberapa penanganan longsoran terdahulu yang telah dilaksanakan, yaitu berupa pemasangan boredpile. Selain itu, terdapat box culvert di bawah badan jalan yang telah mengalami keretakan. Dokumentasi hasil survey pendahuluan ditunjukkan pada Gambar 10 di bawah ini.

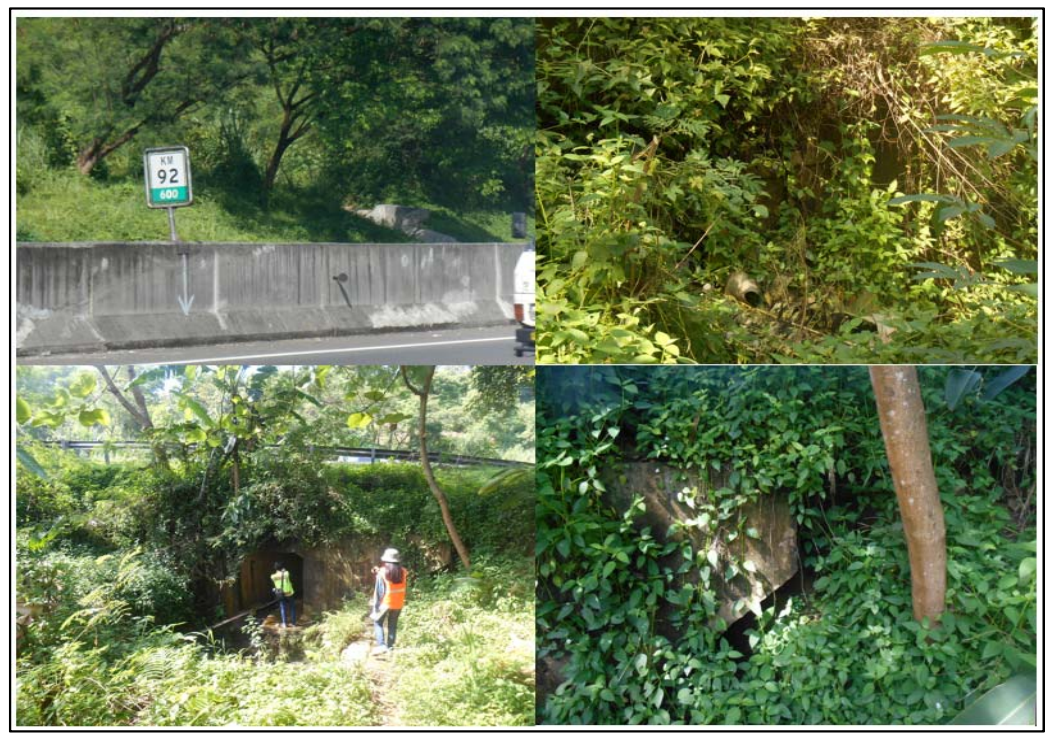

Gambar 10 Dokumentasi lapangan di Km. 92+600.

Rekayasa Hijau - 108 
Pemodelan analisis stabilitas lereng di Km. 92+600 dilakukan di 2 (dua) lokasi, yaitu Km. 92+642 dan $\mathrm{Km} .92+710$. Dalam pemodelan lokasi ini, parameter yang tanah yang digunakan disajikan pada Tabel 2.

Tabel 2 Parameter Tanah yang Digunakan untuk Pemodelan di Km. 92+600

\begin{tabular}{cccccccc}
\hline \multirow{2}{*}{ Lapis } & Jenis Tanah & Tipe & $\gamma_{\text {unsat }}$ & $\gamma_{\text {sat }}$ & Eref & $\mathbf{C}_{\text {ref }}$ & $\boldsymbol{\phi}$ \\
\cline { 4 - 7 } & $\mathbf{k N / \mathbf { m } ^ { 3 }}$ & $\mathbf{k N / \mathbf { m } ^ { \mathbf { 3 } }}$ & $\mathbf{k N / \mathbf { m } ^ { \mathbf { 2 } }}$ & $\mathbf{k N} / \mathbf{m}$ & $\mathbf{0}$ \\
\hline 1 & $\begin{array}{c}\text { Lempung coklat sedikit } \\
\text { berlanau }\end{array}$ & Undrained & 17.06 & 18.06 & 6784 & 18 & 9 \\
\hline 2 & $\begin{array}{c}\text { Lempung kepasiran } \\
\text { halus }\end{array}$ & Undrained & 18.23 & 19.23 & 5824 & 20 & 10 \\
\hline 3 & Pasir lepas hitam & Drained & 23 & 24 & 45960 & 10 & 30 \\
\hline 4 & Pasir halus abu padat & Drained & 23 & 24 & 45960 & 10 & 46 \\
\hline 5 & Batu lempung & Undrained & 23 & 24 & 22500 & 50 & 10 \\
\hline
\end{tabular}

a) Analisis Kestabilan Lereng di Km. $92+642$

Analisis pemodelan dilakukan dalam 2 (dua) kondisi, yaitu kondisi eksisting dan kondisi perkuatan. Pemodelan analisis stabilitas lereng dilakukan dengan metode elemen hingga (FEM). Pemodelan geometri pada kondisi eksisting dan hasil analisis berupa bidang longsor disajikan pada Gambar 11. Pemodelan dilakukan dengan menggunakan parameter tanah hasil uji laboratorium dan korelasi data N-SPT sehingga diperoleh faktor keamanan lereng dari hasil analisis kondisi eksisting ini adalah sebesar 1.035 .

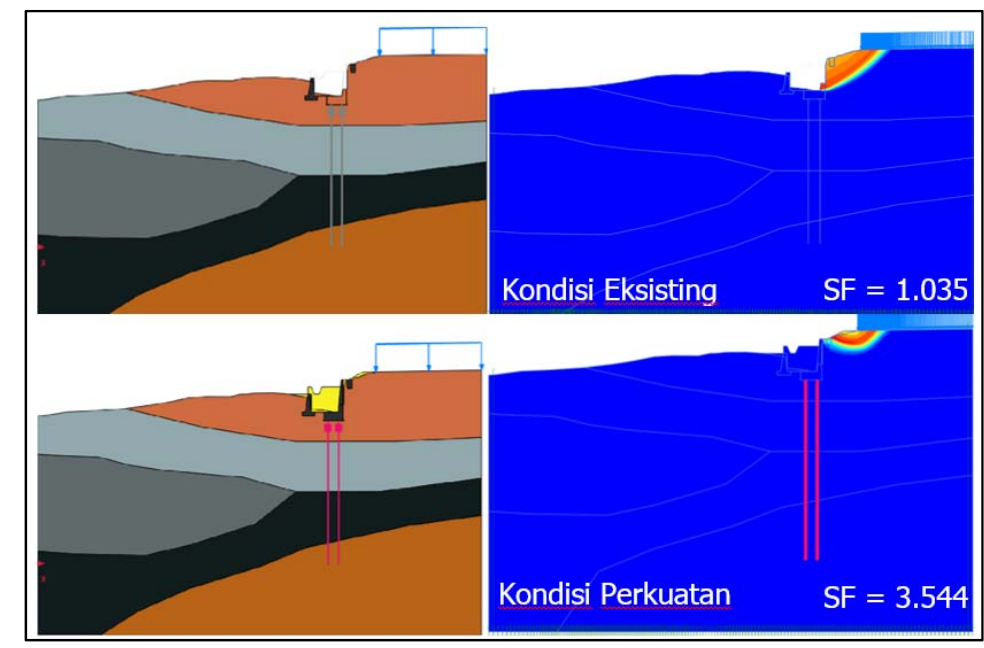

Gambar 11 Hasil analisis kondisi eksisting dan perkuatan di Km. 92+642.

Nilai faktor keamanan yang dihasilkan dari analisis kondisi eksisting kurang dari 1.5, sehingga perlu adanya perkuatan lereng agar menghasilkan nilai faktor keamanan di atas 1.5. Adapun perkuatan lereng yang disarankan yaitu pemasangan dinding penahan tanah dan boredpile yang dipasang 2 (dua) baris dengan pola pemasangan zigzag. Boredpile yang direncanakan berdiameter $80 \mathrm{~cm}$ dan kedalaman tiang $25 \mathrm{~m}$ dengan mutu beton K-350. Hasil analisis pemodelan dengan kondisi perkuatan ditunjukkan pada Gambar 11 dengan nilai faktor keamanan sebesar 3.544.

b) Analisis Kestabilan Lereng di Km. $92+710$

Analisis pemodelan dilakukan dalam 2 (dua) kondisi, yaitu kondisi eksisting dan kondisi perkuatan. Pemodelan analisis stabilitas lereng dilakukan dengan metode elemen hingga (FEM). Pemodelan geometri pada kondisi eksisting dan hasil analisis berupa bidang gelincir disajikan pada Gambar 12. Pada kondisi eksiting terdapat boredpile yang terpasang dengan diameter tiang $1.5 \mathrm{~m}$ dan 
kedalaman tiang $25 \mathrm{~m}$, sehingga diperoleh faktor keamanan lereng dari hasil analisis kondisi eksisting ini adalah sebesar 1.681 .

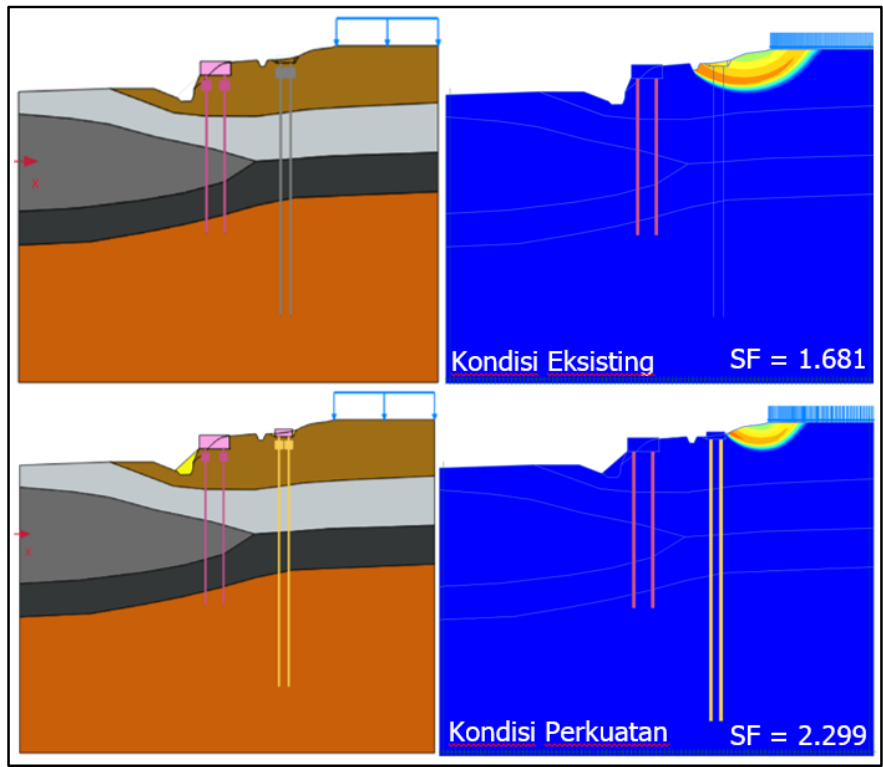

Gambar 12 Hasil analisis kondisi eksisting dan perkuatan di Km. 92+710.

Nilai faktor keamanan yang dihasilkan dari analisis kondisi eksisting lebih dari 1.5, sehingga dapat dikatakan bahwa lereng tersebut aman. Akan tetapi perlu adanya perkuatan lereng karena kondisi di lapangan terdapat adanya pergerakan tanah. Adapun perkuatan lereng yang disarankan yaitu pemasangan pilecap dan boredpile yang dipasang 2 (dua) baris berpola zigzag. Boredpile yang direncanakan berdiameter $80 \mathrm{~cm}$ dan kedalaman tiang $40 \mathrm{~m}$ dengan mutu beton K-350. Hasil analisis pemodelan dengan kondisi perkuatan ditunjukkan pada Gambar 13 dengan nilai faktor keamanan sebesar 2.299.

\subsection{Hasil Analisis Stabilitas Lereng di Jalan Tol Cipularang}

Analisis dengan perkuatan dilakukan pada beberapa cross, baik itu di Km. 91+200 maupun Km. $92+600$. Adapun hasil analisis dengan perkuatan boredpile di Km. 91+200 dan Km. 92+600 menunjukkan nilai SF $>1.5$. Rekapitulasi dari analisis dengan perkuatan disajikan pada Tabel 3 di bawah ini.

Tabel 3 Rekapitulasi Hasil Analisis Stabilitas Lereng di Jalan Tol Cipularang

\begin{tabular}{|c|c|c|c|c|c|}
\hline No & $\mathbf{K m}$ & Titik & SF eksisting & SF perkuatan & $\begin{array}{c}\text { Presentase } \\
\text { Kenaikan SF }\end{array}$ \\
\hline 1 & \multirow{6}{*}{$91+200$} & $91+250$ & 1.148 & 1.567 & $36.5 \%$ \\
\hline 2 & & $91+256.081$ & 1.243 & 1.511 & $21.56 \%$ \\
\hline 3 & & $91+270$ & 1.419 & 1.969 & $38.76 \%$ \\
\hline 4 & & $91+300$ & 1.454 & 1.752 & $20.50 \%$ \\
\hline 5 & & $91+340$ & 1.473 & 1.609 & $9.23 \%$ \\
\hline 6 & & $91+400$ & 1.672 & \multicolumn{2}{|c|}{ Tidak ada penanganan } \\
\hline 7 & \multirow{2}{*}{$92+600$} & $92+642$ & 1.035 & 3.544 & $242.4 \%$ \\
\hline 9 & & $92+710$ & 1.681 & 2.299 & $36.76 \%$ \\
\hline
\end{tabular}

Hasil analisis menunjukkan adanya kenaikan nilai faktor kemanan dari setiap pemodelan. Pada Tabel 3 ditunjukkan bahwa pada Km. 91+250 presentase kenaikan faktor keamanan setelah adanya perkuatan adalah sebesar 36.5\%, pada Km. 91+256.081 sebesar 21.56\%, di Km. 92+270 adalah sebesar 38.76\%, pada Km. 91+300 sebesar 20.50\%, dan Km. 91+340 sebesar 9.23\%. Adapun 
presentase kenaikan nilai faktor keamanan di Km. $92+600$ yaitu sebesar $242.4 \%$ dan pada $\mathrm{Km}$. $92+710$ sebesar $36.76 \%$.

\section{KESIMPULAN}

Setelah dilakukan analisis pada pemodelan lereng di Jalan Tol Cipularang Km. 91+200 dan Km. $92+600$, dapat disimpulkan bahwa kondisi eksisting lereng dominan kurang aman karena diperoleh nilai faktor keamanan kurang dari 1.5. Sehingga dibutuhkannya sebuah penanganan longsoran yang efektif dan tepat serta permanen.

Penanganan longsoran dengan menggunakan dinding penahan tanah dan boredpile disarankan dalam masalah ini, karena efektif yang dapat dilihat dari kenaikan nilai faktor keamanan dari kondisi eksisting dan kondisi perkuatan. Adapun presentase kenaikan nilai faktor keamanan terendah pada pemodelan di Km 91+240, yaitu sebesar 9.23\%. Sedangkan kenaikan presentase nilai faktor kemanaan terbesar terdapat di pemodelan Km. 92+642, yaitu sebesar $242.4 \%$.

\section{DAFTAR PUSTAKA}

[1] Brinkgreve R B J. et al, R. F, (2016) Reference Manual, Spon Press, PLAXIS, Netherlands.

[2] Coulomb, C. A. (1776) Essai sur une application des regles de Maximums et Minimis a quelques Problemes de Statique, relatifs a 1'Archtecture, Memoires de Mathematique et de Physique, Presentes, a 1'Academie Royale des Sciences, Paris. Vol.3, 38.

[3] Craig, R. F, (2004) Craig's Soil Mechanics, Seventh Edition, Spon Press, Department of Civil Engineering University of Dundee UK.

[4] Direktorat Jenderal Bina Marga (PU), (1987) Buku Petunjuk Teknis Perencanaan dan Penanganan Longsoran. Yayasan Penerbit PU. Jakarta, Indonesia.

[5] Mohr, O. (1900). Welche Umstande Bedingen die Elastizitatsgrenze und den Bruch eines Materiales? Zeitschirft des Vereines Deutscher Ingenieure. Vol. 44, 1524-1530, 1572-1577.

[6] Rahardjo, P. P., (2012) Manual Kestabilan Lereng, UNPAR. 